\begin{tabular}{|c|c|c|}
\hline Case Reports in & \multicolumn{2}{|c|}{ Case Rep Gastroenterol 2019;13:445-449 } \\
\hline Gastroenterology & $\begin{array}{l}\text { DOI: 10.1159/000503898 } \\
\text { Published online: October 30, } 2019\end{array}$ & $\begin{array}{l}\text { (c) } 2019 \text { The Author(s) } \\
\text { Published by S. Karger AG, Basel } \\
\text { www.karger.com/crg }\end{array}$ \\
\hline & $\begin{array}{l}\text { This article is licensed under the } \\
\text { International License (CC BY-NC) } \\
\text { Usage and distribution for commerc }\end{array}$ & $\begin{array}{l}\text { nons Attribution-NonCommercial } 4.0 \\
\text { ger.com/Services/OpenAccessLicense). } \\
\text { uires written permission. }\end{array}$ \\
\hline
\end{tabular}

\title{
Esophageal Nikolsky's Sign: A Rare Finding in a Patient with Bullous Pemphigoid
}

\author{
Sara Ghoneim ${ }^{\mathrm{a}} \quad$ Aun Shah $^{\mathrm{a}} \quad$ Amy Calderon $^{\mathrm{b}}$ \\ aDepartment of Internal Medicine, Case Western Reserve University at MetroHealth \\ Medical Center, Cleveland, OH, USA; bivision of Gastroenterology and Hepatology, Case \\ Western Reserve University at MetroHealth Medical Center, Cleveland, $\mathrm{OH}$, USA
}

\section{Keywords}

Bullous pemphigoid · Melena · Esophagogastroduodenoscopy · Esophageal Nikolsky's sign

\begin{abstract}
Bullous pemphigoid (BP) is a chronic relapsing autoimmune blistering disease that typically affects middle-age and elderly patients. It can manifest with varying degrees of mucosal involvement in addition to characteristic skin findings. However, esophageal involvement is very rare. We report a case of a 57-year-old female with BP who presented with epigastric pain and melena. She underwent an esophagogastroduodenoscopy which induced bullae seen only upon withdrawal of the endoscope. This finding is analogous to the dermatological finding of Nikolsky's sign. Gentle insertion and withdrawal of the endoscope is recommended to reduce the risk of bullae formation and mucosal injury.

(C) 2019 The Author(s) Published by S. Karger AG, Basel
\end{abstract}

\section{Introduction}

Bullous pemphigoid (BP) and mucous membrane pemphigoid (MMP) disorders are chronic relapsing autoimmune blistering diseases characterized by circulating antibodies directed against specific epitopes of hemidesmosomes involved in anchoring the epidermis to the dermal layer [1-3]. Tense bullae on the skin distinguish these 2 entities from the more flaccid bullae seen in pemphigus vulgaris [2]. Formation of new bullae on application of 


\section{Case Reports in Gastroenterology}

Case Rep Gastroenterol 2019;13:445-449

DOI: $10.1159 / 000503898$

(c) 2019 The Author(s). Published by S. Karger AG, Basel www.karger.com/crg

Ghoneim et al.: Esophageal Nikolsky's Sign: A Rare Finding in a Patient with Bullous Pemphigoid

pressure to skin is known as Nikolsky's sign and helps clinically differentiate pemphigus vulgaris from BP. However, this sign can be rarely seen with other bullous dermatoses as well [4]. Whereas BP typically affects the skin, the mucous membranes are predominately affected in MMP [3]. Antigens identified in MMP include BP180, BP230, Laminin 5/6, Type VII collagen, and Integrin 4 subunit [2, 3, 5], whereas only BP180 and BP230 are involved in BP [2]. Esophageal involvement in BP is quite rare and generally manifests as hemorrhagic bullae [1, 6-13]. We report a case of acute-onset esophageal bullae identified in a patient with active skin BP seen only upon withdrawal of the upper endoscope, not present on insertion. This sign is analogous to Nikolsky's sign where pressure or shearing results in formation of new bullae.

\section{Case Presentation}

A 57-year-old Caucasian female with type II diabetes, BP, and chronic kidney disease stage 3a presented to our hospital with epigastric pain and 5-6 episodes of melanotic stools that started 2 days prior. She was using Ibuprofen $600 \mathrm{mg}$ every $6 \mathrm{~h}$ to alleviate the pain. She endorsed dizziness but denied dysphagia, hematochezia, or hematemesis. The patient was diagnosed in September 2017 with BP confirmed by skin biopsy (Fig. 1). Direct immunofluorescence findings at that time showed linear deposits of $\mathrm{IgG} / \mathrm{C} 3$ against the dermo-epidermal junction. At that time, she was started on oral prednisone and mycophenolate.

On admission, she was hemodynamically stable. Skin examination was notable for tense bullae involving the upper extremities (Fig. 2). Digital rectal exam revealed melena. Laboratory findings were significant for a hemoglobin level of $5.7 \mathrm{mg} / \mathrm{dL}$ and a hematocrit of 17.5 $\mathrm{mg} / \mathrm{dL}$. The patient received 2 units of packed red blood cells, started on a proton pump inhibitor infusion, and continued on home dose of mycophenolate and oral prednisone. She underwent an esophagogastroduodenoscopy which revealed a $1.5-\mathrm{cm}$ clean based, Forrest III deep cratered ulcer with heaped edges in the duodenal bulb. Sloughing of the mucosa was seen in the esophagus. Interestingly, multiple fluid-filled bullae were visualized in the upper and lower esophagus only upon withdrawal of the endoscope and not during initial insertion (Fig. 3). She remained stable after the procedure and had no further episodes of melena. She was discharged home on a high-dose oral proton pump inhibitor, mycophenolate, oral prednisone, and topical steroid ointment.

\section{Case Discussion}

Pemphigoid disorders are autoimmune dermatologic conditions which encompass BP and MMP [14]. BP is the most common type of autoimmune blistering disease affecting older adults, generally in the 8th decade of life without gender predilection $[2,14]$. The classical finding in BP are tense fluid-filled bullae on the skin. MMP is a more aggressive variant of BP; it is a mucous membrane-dominant autoimmune subepithelial blistering disease that predominately affects the mouth, larynx, oropharynx, or esophagus [14]. The gold standard test in diagnosis relies on a skin biopsy involving the perilesional site. Direct immunofluorescence is performed on the sample obtained from the perilesional site. Linear deposits of IgG and/or C3 along the basement membrane zone (BMZ) are consistent with the diagnosis of BP. Circulating antibodies that recognize self-antigens within the BMZ with subsequent Fc-mediated complement and inflammatory cell activation play a key role in the development of pemphigoid disorders. However, it remains very challenging to classify various autoimmune bullous 
dermatoses due to the incomplete characterization of the anchoring molecules within the BMZ. Patients with BP have increased risk of mortality compared to the general population [15]. The involvement of the esophagus in BP is very rare, with a few cases reported in the literature [6-13]. The esophageal manifestations of BP are often nonspecific, and the clinical presentation may be dysphagia, hematemesis, melena, or hemodynamic instability due to brisk upper gastrointestinal bleeding. The use of esophagogastroduodenoscopy can be challenging in patients with BP because of bullae formation and mucosal sloughing after light contact between esophageal mucosa and the endoscope. Gentle advancement and withdrawal of the endoscope is advised to prevent adverse events, such as hemorrhagic bullae formation, frank bleeding, or perforation. Management generally depends on the severity of the presentation and typically progresses from topical steroids to oral antibiotics, systemic steroids, and immunosuppression therapy. In case of significant gastrointestinal bleeding and/or hemodynamic instability, therapeutic endoscopy can be used to achieve hemostasis. Alternatively, the use of argon plasma coagulation which does not require direct contact with mucosa can been attempted to treat esophageal bleeding due to rupture of hemorrhagic bullae [15].

In conclusion, our patient had biopsy-proven BP with skin involvement and later on developed esophageal bullae upon withdrawal of the endoscope. This "endoscopic Nikolsky's sign" is observed very rarely and highlights the susceptibility of mucosa to shearing by way of epidermal-dermal separation. Care must be taken in such patients with gentle insertion and withdrawal of the endoscope, lest risking complications form mucosal injury and bullae formation.

\section{Statement of Ethics}

Informed consent was obtained for this case report

\section{Disclosure Statement}

The authors have no conflicts of interest to declare.

\section{Funding Sources}

No external funding was used for this case report.

\section{Author Contributions}

Ghoneim, S., Shah, A., and Calderon, A., wrote, edited, and approved the final version. Ghoneim, S., wrote, edited, revised, and approved the final version of the manuscript and she is the article guarantor. 
Ghoneim et al.: Esophageal Nikolsky's Sign: A Rare Finding in a Patient with Bullous Pemphigoid

\section{References}

1 Wise JL, Murray JA. Esophageal manifestations of dermatologic disease. Curr Gastroenterol Rep. 2002 Jun;4(3):205-12.

2 Miyamoto D, Santi CG, Aoki V, Maruta CW. Bullous pemphigoid. An Bras Dermatol. 2019 Mar-Apr;94(2):13346.

3 Kamaguchi M, Iwata H. The Diagnosis and Blistering Mechanisms of Mucous Membrane Pemphigoid. Front Immunol. 2019 Jan;10:34.

4 Venugopal SS, Murrell DF. Diagnosis and clinical features of pemphigus vulgaris. Dermatol Clin. 2011 Jul;29(3):373-380, vii.

5 Chong VH, Lim CC, Vu C. A rare cause of acute upper gastrointestinal bleeding. Surg Laparosc Endosc Percutan Tech. 2006 Apr;16(2):91-3.

6 Maharshak N, Sagi M, Santos E, Sprecher E, Goldberg I. Oesophageal involvement in bullous pemphigoid. Clin Exp Dermatol. 2013 Apr;38(3):274-5.

7 Eng TY, Hogan WJ, Jordon RE. Oesophageal involvement in bullous pemphigoid. A possible cause of gastrointestinal haemorrhage. Br J Dermatol. 1978 Aug;99(2):207-10.

8 Sharon P, Greene ML, Rachmilewitz D. Esophageal involvement in bullous pemphigoid. Gastrointest Endosc. 1978 Feb;24(3):122-3.

9 Gaspar R, Moutinho-Ribeiro P, Macedo G. Bullous pemphigoid: extensive esophageal involvement. Gastrointest Endosc. 2017 Aug;86(2):400-2.

10 McFarlane M, Azam A, Snead D, Disney B. Oesophageal pemphigoid: a rare cause of dysphagia. Clin J Gastroenterol. 2019 Feb;12(1):25-8.

11 Lee CM, Leadbetter HK, Fishman JM. A case of oropharyngeal bullous pemphigoid presenting with haemoptysis. Case Rep Otolaryngol. 2015;2015:631098.

12 Schmidt E, Zillikens D. Pemphigoid diseases. Lancet. 2013 Jan;381(9863):320-32.

13 Murrell DF, Marinovic B, Caux F, Prost C, Ahmed R, Wozniak K, et al. Definitions and outcome measures for mucous membrane pemphigoid: recommendations of an international panel of experts. J Am Acad Dermatol. 2015 Jan;72(1):168-74.

14 Rzany B, Partscht K, Jung M, Kippes W, Mecking D, Baima B, et al. Risk factors for lethal outcome in patients with bullous pemphigoid: low serum albumin level, high dosage of glucocorticosteroids, and old age. Arch Dermatol. 2002 Jul;138(7):903-8.

15 Nagashima R, Tsuge K, Harada M, Katagiri Y, Shinzawa H, Takahashi T. Endoscopic hemostasis of hemorrhage from esophageal bullous pemphigoid. Gastrointest Endosc. 2000 Sep;52(3):433-4.

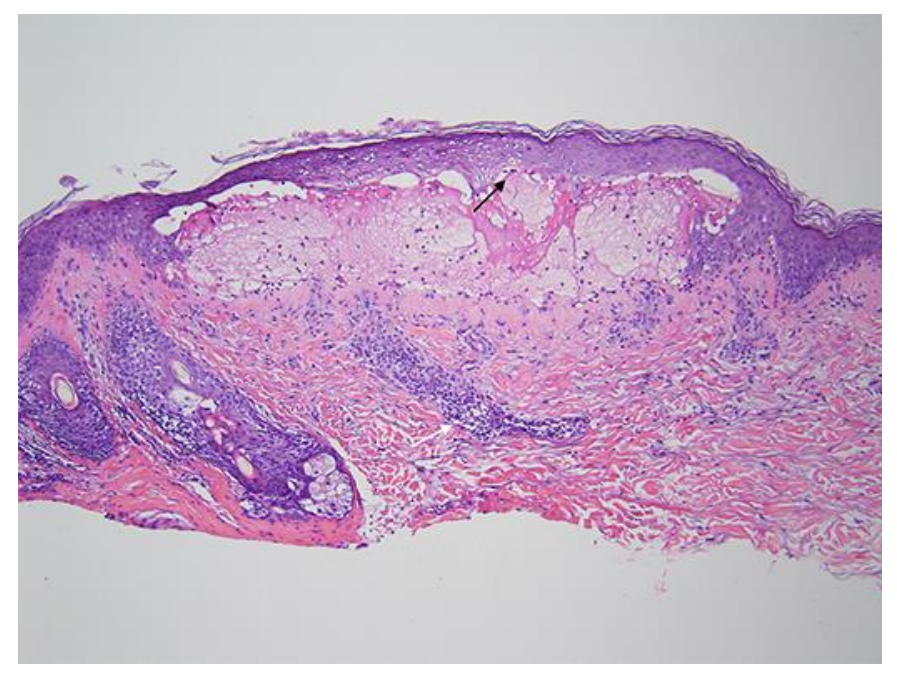

Fig. 1. Perilesional biopsy of patient with BP. HE, $\times 10$. Subepidermal blister formation with numerous eosinophils is visible within the cleft (black arrow). There is perivascular infiltration with eosinophils (white arrow). 


\section{Case Reports in \\ Gastroenterology}

\begin{tabular}{l|l}
\hline Case Rep Gastroenterol 2019;13:445-449 \\
\hline DOI: 10.1159/000503898 & $\begin{array}{l}\text { c 2019 The Author(s). Published by S. Karger AG, Basel } \\
\text { www.karger.com/crg }\end{array}$ \\
\hline
\end{tabular}

Ghoneim et al.: Esophageal Nikolsky's Sign: A Rare Finding in a Patient with Bullous Pemphigoid

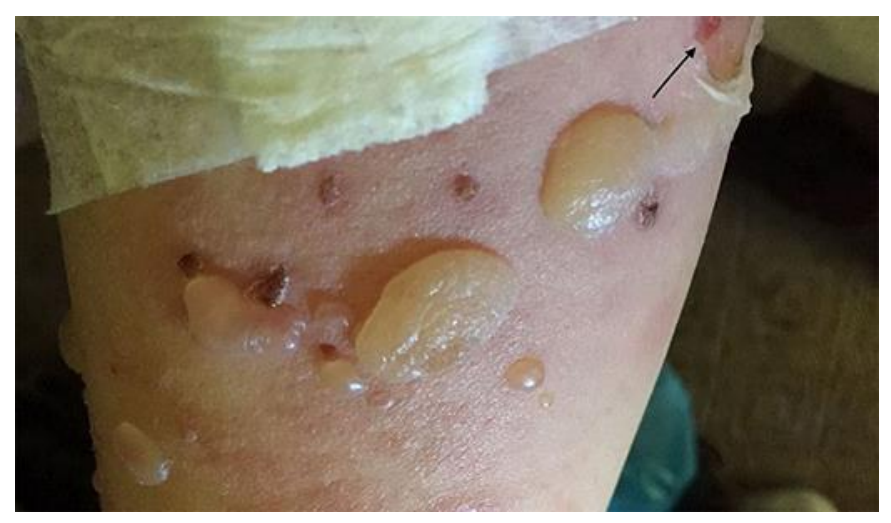

Fig. 2. Multiple tense bullae on the right forearm of the patient with BP. Unroofed blister on the upper medial aspect of the forearm (black arrow).
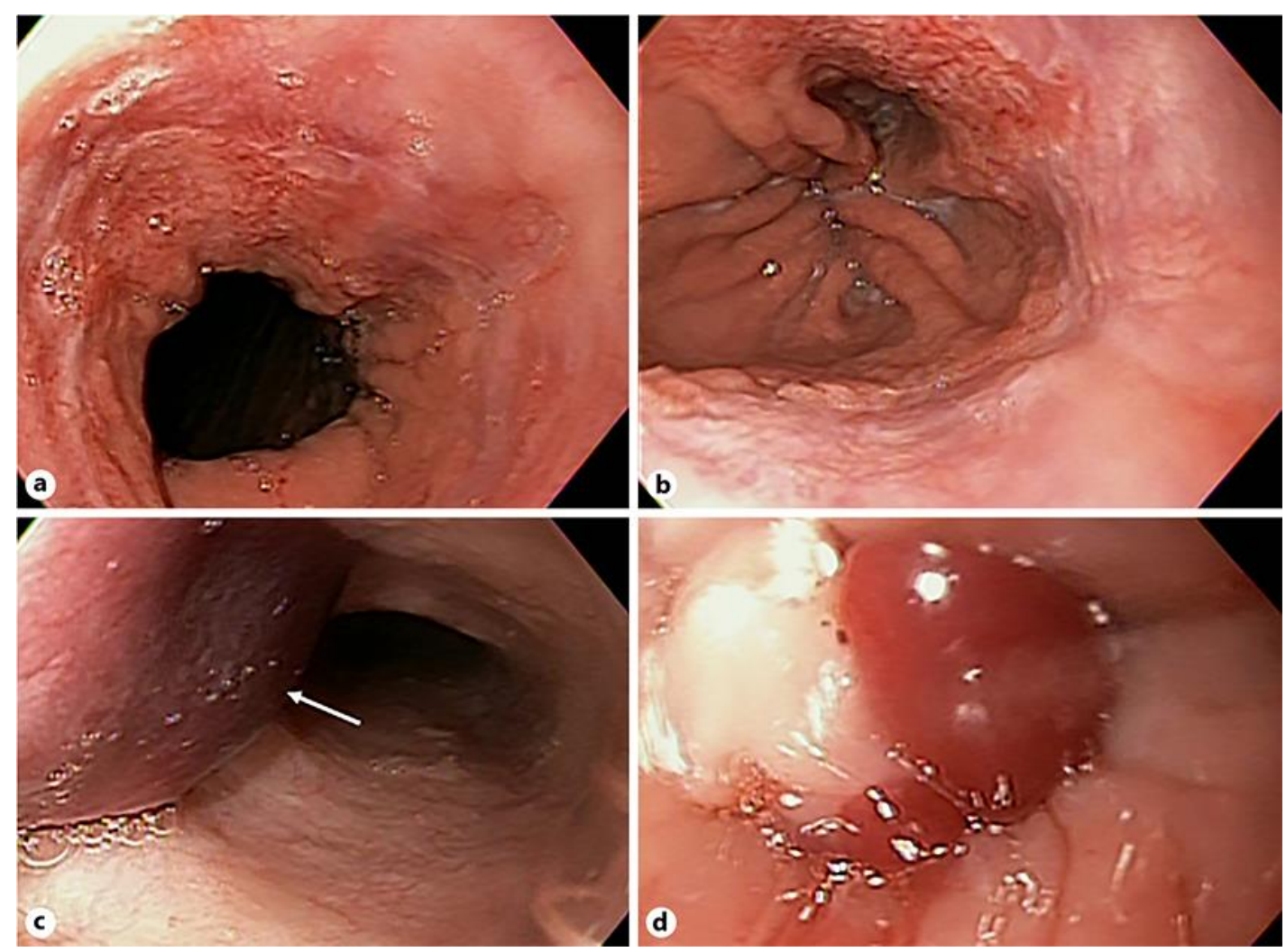

Fig. 3. a Upper esophagus seen on insertion. b Lower esophageal sphincter/hiatal hernia on insertion. c Large blood blister can be seen in the lower esophagus on withdrawal (white arrow). d Small bullae/blood blister can be seen in the upper esophagus on withdrawal. 